\title{
Health Problems among Women Building Construction Workers
}

\author{
Nahid Sultana ${ }^{1}$, Jannatul Ferdousi ${ }^{2}$, Md. Shahidullah ${ }^{3}$
}

\begin{abstract}
Back ground: Construction industry is one of the stable growing industries world over, including Bangladesh. In Dhaka city there are many construction sites, where workers are exposed to hazardous condition, specially the female workers. Throughout the world, over $90 \%$ of construction workers are male. In some developing countries, the proportion of women is higher. In Bangladesh their number is increasing day by day. Objective: To explore the health problems among the women building construction workers Methods: This cross-sectional study was carried out among 134 female construction workers. Data was collected through face to face interview by using prefixed questionnaire. The study was conducted from September 2011 to December 2012 in the Department of Community medicine, Dhaka National Medical College, Dhaka. The subjects were selected from different building construction sites of old Dhaka city. Results: It was observed that among 134 respondents, majority $96(71.6 \%)$ of the women construction worker were brick breaker and 38(28.3\%) were weight carrier. Their mean age was 38.29 \pm 6.9 years. Most workers $110(82.1 \%)$ had different types of skin problem. The proportion of skin problems was found to be high among the weight carrier and the difference was statistically highly significant (pE .001). 89(66.5\%) respondents had urinary tract infection, 66(49.3\%) had constipation and 24(17.9\%) complaint uterine prolapse. Among the total respondents 68(58.2\%) complain of backache. The workers who complain of backache, 52(54.1\%) were brick breaker and $16(42.1 \%)$ were weight carrier. $79(58.9 \%)$ respondents used personal protective equipments, among them $61(77.2 \%)$ used self made hand gloves and 38(48.1\%) used folded towel to carry weight. Besides of the total respondents $117(87.3 \%$ ) complain of different types of respiratory problem. Conclusion: The study concludes that different types of skin diseases are present among female construction workers that might be attributable to exposure to hot humid working environment. Besides pain full micturation, uterine prolapse, low backache and respiratory problem were found among them which might need special attention.
\end{abstract}

Key words: Construction worker, PPE (personal protective equipment), UTI (urinary tract infection), uterine prolapsed.

Bangladesh Soc Physiol. 2014, June; 9(1): 31-36

For Authors Affiliation, see end of text.

http://www.banglajol.info/index.php/JBSP

\section{Introduction}

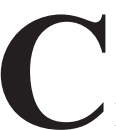
onstruction is one of the important industries employing a large number of people on its workforce. Construction industry is one of the stable growing industries

Received Feb. 2014;

Accepted April 2014

J Bangladesh Soc Physiol. 2014, June; 9(1): 31-36 of the world and construction labour form $7.5 \%$ of the world labour force. ${ }^{1}$ A wide range of activities are involved in it and the workers engaged in this industry are victims of different occupational disorders and psychosocial stresses. It is true that a sizable number of the 
workforce is from the unorganized sectors, the working hours are more than the stipulated hours of work, the work place is not proper, the working conditions are non-congenial in most of the cases and involves risk factors. Their wages are also not adequate, making it difficult for them to run their families. The hazards include handling of different materials required for construction, and exposure to harsh environmental conditions like sun, rain, and so on, which result in accidents and adverse health conditions cause psychosocial strain. They are victims of headache, backache, joint pains, skin diseases, lung disorders like silicosis, other musculoskeletal disorders, and so on. ${ }^{2}$ Construction worker are exposed to multiple risks at working and living places. They are exposed to physical, chemical, biological, ergonomic hazards and environmental and psychosocial risks. ${ }^{3}$ The labour force of Bangladesh is estimated to be about $47 \%$ of the total population. At least 16 occupational diseases have been observed in the country, but none has been reported. ${ }^{4} \mathrm{~A}$ large portion of construction workers are unskilled laborers. Construction workers include about 5 to $10 \%$ of the workforce in industrialized countries. Women are almost unskilled labourers and they face serious problems related to work, viz., wage discrimination, gender and sexual harassment, unhealthy job relationship, lower wages; despite these, construction industry over whelmingly attracts female workers besides Their skills are never upgraded as they are allowed to perform only certain types of work and usually they assist the male work force. ${ }^{5}$

Although the development of technology with sophisticated machinery has beings in most sectors of life, the construction work is still labour-intensive. In the developing world, most construction workers have to perform high risk work for meager wages. There are only few industries as hazardous as construction work. Work at elevation, work involving heavy overhead loads, operation of heavy machinery and power tools, confined space work, temperature extremes and material handling demands combine to increase the risk of injuries. The construction workers are regarded as the prototype of extremely demanding jobs tagged as 3-D's: dirty, dangerous and difficult. ${ }^{6}$

The Health and Safety Executive (HSE-2002) states that construction has a reputation for being a particularly unhealthy industry because its rate of work related illness is one of the highest of all occupational groups. Health problems among this group are relevant because of the number of high risk activities involved, and the peripatetic nature of the workforce ${ }^{7}$ Construction workers are exposed to risks that differ markedly from general industry Related to occupational health and safety. Workers are exposed to variety of health hazards, namely musculoskeletal strain from the adaptation of uncomfortable working position, noise resulting in noise induced hearing loss. Skin diseases from close contact with irritant or sensitizing materials, respiratory irritant from dusts, fume and gases, as well as developing more serious lung diseases related to exposure to asbestos and other fibrogenic materials. ${ }^{8}$ However, a few studied had done in abroad regarding this issue but no published data is available in Bangladesh. So the study was undertaken to explore the health problems among female construction worker in Bangladesh.

\section{Methods}

This cross sectional study was carried out among 134 married female building construction workers who were working in different construction sites in old Dhaka city. All participants were belonged to low socioeconomic class. Their mean age was $38.29 \pm 6.9$ years. The study was conducted during September 2011 to December 2012 in the Department of Community Medicine, Dhaka National Medical College, Dhaka. Purposive sampling was done to select the sample. A preset semi structured questionnaire was used to collect data. The data was collected by face to face interview of the respondents. For statistical analysis chi square test was done. 


\section{Results}

The mean $( \pm \mathrm{SD})$ of age, daily income and working hour per day of the workers are shown in table I.

Table I: Distribution of respondents by age, working hours and income

\begin{tabular}{lcc}
\hline Age (years) & $\begin{array}{c}\text { Working } \\
\text { hour/day }\end{array}$ & $\begin{array}{c}\text { Income } \\
\text { (taka)/day }\end{array}$ \\
\hline $38.29 \pm 6.9$ & $7.8 \pm .54$ & $222.10 \pm 53.64$ \\
\hline
\end{tabular}

Among the total respondents $74(55.2 \%)$ had latrine facilities in their working place and $60(44.8 \%)$ had no such facilities. Of the total respondents $97(72.6 \%)$ got drinking water from supplied water, 34(25.4\%) from tube well, 3(2.2\%) from other sources.(Figure I) and (Figure II)

Latrine facility in work place

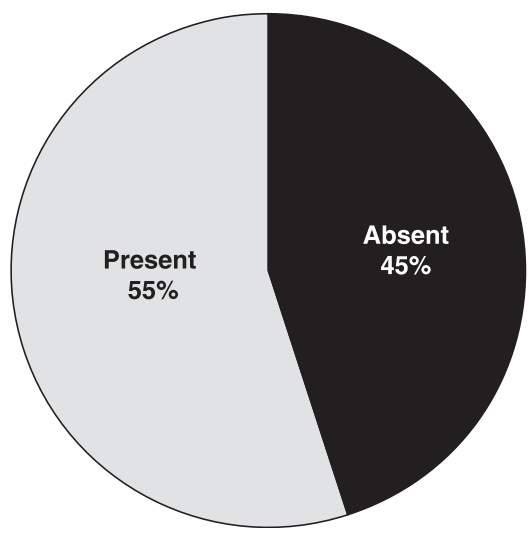

Figure I: Distribution of respondents by latrine facilities

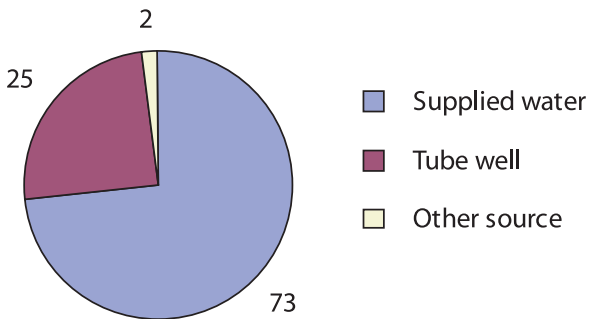

Figure II: Distribution of the respondents by drinking water facility in work place

J Bangladesh Soc Physiol. 2014, June; 9(1): 31-36
Figure III shows that highest percentage $95(70.8 \%)$ complaint of dust was the major hazards in their work place, 39(29.1\%) complaint injuries of different types, $83(61.9 \%)$ heat and $37(27.6 \%)$ moisture. Though majority complaint about dust in work place but no worker use musk as PPE, among the total respondents 79 (58.9\%) respondents used PPE (personal protective equipments), among them 61(77.21\%) used self made hand gloves and 38(48.1\%) used folded towel to carry weight.(Figure IV)

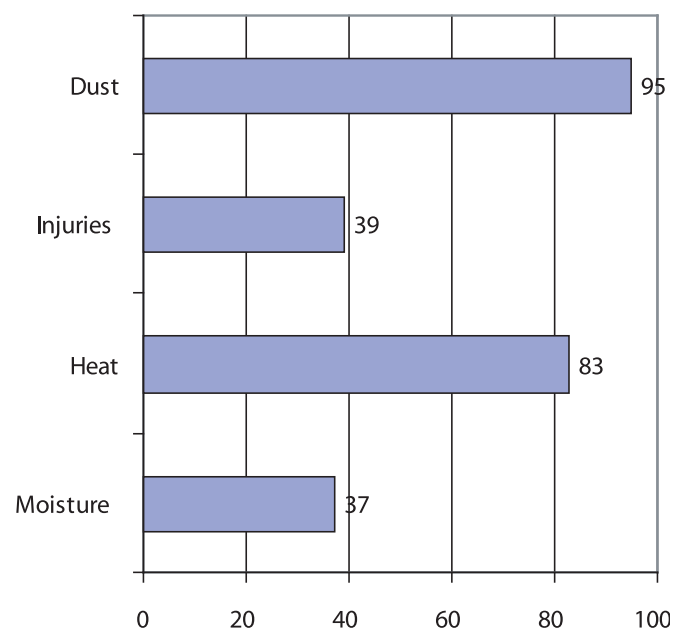

Figure III: Distribution of the respondents by work place problem

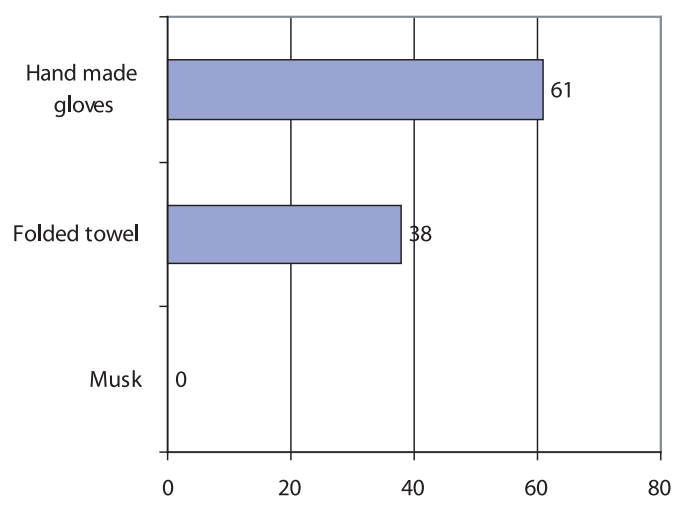

Figure IV: Distribution of the respondents by using of personal protective equipments 
Table II depicts that among the total respondents, $89(66.5 \%)$ worker had complaint of pain during micturation and $45(33.5 \%)$ had no such complaint $.68(50.7 \%)$ worker were found to be suffering from backache among them 52(76.5\%) were brick breaker and $16(23.5 \%)$ were weight carrier. It also shows that among the total workers $66(49.3 \%)$ respondents had constipation and $68(50.7 \%)$ had no such complain.24 (17.9\%) complaint about vaginal prolapse, rest had any such complaint. The differences of occurrence of such problems were not statistically significant.

In this study majority $110(82.1 \%)$ had different types of skin problem. Among them 34(30.9\%) had rash, 67(60.9\%) had rash with itching and $17(15.4 \%)$ had fungal infection. The proportion of skin problems was found to be high among the weight carrier and the difference was statistically significant $(\mathrm{p}=.001)$. (Table III)

This study explore in Figure that, of the total respondents $117(87.3 \%)$ had respiratory problems, among them, $42(31.3 \%)$ suffering from respiratory distress like chest tightness and shortness of breath, 12(9.0\%) from running nose, $27(20.1 \%)$ from chronic cough, 36(26.9\%) from both chronic cough and running nose and $17(12.7 \%)$ had no such complaint

Table II: Distribution of number of respondents by work related health problems

\begin{tabular}{lcccccc}
\hline Type of work & \multicolumn{2}{c}{ UTI } & \multicolumn{2}{c}{ Backache } & \multicolumn{2}{c}{ Uterine Prolapse } \\
& Present & Absent & Present & Absent & Present & Absent \\
\hline Brick breaker & 68 & 28 & 52 & 44 & 14 & 82 \\
Weight carrier & 21 & 17 & 16 & 22 & 10 & 28 \\
Test of significance & $\mathrm{X}^{2}=2.95 \mathrm{p}=.085$ & $\mathrm{X}^{2}=1.58$ & $\mathrm{p}=.208$ & $\mathrm{X}^{2}=2.54 \mathrm{p}=.110$ \\
\hline
\end{tabular}

Data were expressed as percentage. Statistical analysis was done by chi-square test to see any association between pattern of work and health problem like UTI, backache, uterine prolapsed. Statistically found no significant.

Table III: Distribution of respondents by skin problems

\begin{tabular}{lcccc}
\hline Skin problems & Brick breaker & $\begin{array}{c}\text { Type of work } \\
\text { Weight carrier }\end{array}$ & Total & $\mathrm{X}^{2-11.57 \mathrm{p}<.001}$ \\
\hline Present & 72 & 38 & 110 & \\
Absent & 24 & 00 & 24 & \\
\hline & 96 & 38 & 134 & \\
\hline
\end{tabular}

Data express by percentage distribution. Statistical analysis was done by chi-square. The proportion of skin problems was found to be high among the weight carrier and the difference was statistically highly significant $(\mathrm{p}=.001)$

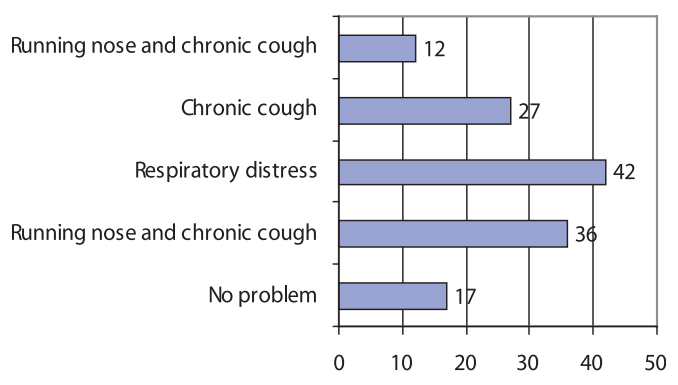

Figure 5: Distribution of respondents by respiratory problems

\section{Discussion}

This study has been carried out to find out the health problems among the women building construction workers. In this study various type of skin problems were found. Similar findings were found in other study, where $18(19.6 \%)$ of the subject had frictional callosities in their palm, $4(4.3 \%)$ had contact dermatitis and $2(2.2 \%)$ had infectious skin disease. ${ }^{3}$ Contact with cement and lime may lead to irritant dermatitis. The presence of chromate and cobalt in cement

J Bangladesh Soc Physiol. 2014, June; 9(1): 31-36 
is known to cause allergic contact dermatitis .Scarcity of water, limited availability of cleaning facilities and climate conditions hasten the development of dermatitis in construction worker. ${ }^{9}$ In this study 89 (66.5\%) respondents had UTI, 66 (49.3\%) had constipation,35 (17.4\%) complaint about uterine prolapsed. The risk factors for prolapse were mentioned in some study, where it was mentioned that illiteracy, multiparity. Poverty, home delivery, early age at marriage, less rest time after delivery and hard work act as risk factors for uterine prolapse. ${ }^{10}$ Dust, injuries, heat and moisture were mentioned as problem in workplace in this study. In some study it was mentioned that, the risk of accidents increase with extremes of temperature, age, sex, personal habit (like working under influence of alcohol), personality traits (risk taking behavior) .Besides physical and mental state of the worker play an important role in the occurrence of accidents ${ }^{11}$ In this study some respondents complain of backache. Construction worker have got an attributable risk of $50 \%$ for musculoskeletal injuries, higher then all other worker. Postural changes like bending forward or standing and weight bearing may cause backache, low back pain, neck pain and so on. ${ }^{4}$ In this study many respondents use hand made glove to prevent injury folded towel to carry weight but no respondents use musk where they mentioned respiratory problems and mentioned dust as one of the hazards in work place. In other study, only $42(45.7 \%)$ of the subject were using one or the other personal protective devices. ${ }^{3}$ high level of illiteracy affects their knowledge regarding the use of personal protective devices. ${ }^{12}$ some respondents reported different types of respiratory problems. In another study who were periodically working in the construction industry, reported diverse types of respiratory complaints. ${ }^{11}$ Inhalation of cement dust can cause respiratory disorders and difficulty in breathing ${ }^{13}$

J Bangladesh Soc Physiol. 2014, June; 9(1): 31-36

\section{Conclusion}

The findings of this study revealed that different types of health problems were prevalent amongst the workers in construction industry. The workers were young adult and belonged to poor socioeconomic stratum of the society. They did not have any knowledge about the hazardous substances in their working place and proper use of PPE. Necessary measures should be taken to protect the workers by reducing exposure to prevailing hazards. In addition to that the workers should be aware regarding the hazards in their working place.

\section{Author affiliation}

1. Dr. Nahid Sultana, Associate Professor, Department of Community Medicine. Dhaka National Medical College.Email:dr_nahidsultana@yahoo.com

2. Dr. Jannatul Ferdousi, Associate professor, Department of Community Medicine, Dhaka National Medical College. Email:jannatulrita @yahoo.com

3. Dr. Md. Shahidullah, Assistant Professor, Department of Neurology, BSMMU. Email:sabuj23 (a)gmail.com

\section{Acknowledgement}

Students of N16 batch Dhaka National Medical College and also worker who give their valuable time for this study

\section{References}

1 Shah KR,Twari RR.Occupational skin problems in construction workers.Indian.J. Dermatol.2010; 55:348-51 Available from:httpHYPERLINK "http://www.e-ijd.org/text.asp?2010/55/4/348/ 74537"://www.e-ijd.org/text.asp?2010/55/4/348/ 74537

2 Tiwary G,gangopathyay PK.A review on the occupational health and social security of unorganized workers in the construction industry.Indian J.Occup Environ Med.2011;15:18-24

3 Jayakrishnan TThomas B, Rao B, George B.Occupational health problems of construction worker in India.Int.J.Med Public Health.2013; 3:225-9. Available from: http://www.injmedph.org/ text.asp:2013/314/225/123414 
4 Rashid KM,Rahman M, Hyder S.Rashid,khabir, Hyder's Textbook of Community Medicine and Public Health.4th edi.RHM Publishers, Dhaka,2004:388

5 Kalpana D, U.V. Kiran, status of female worker in Construction industry in India: A review journal of Humanities and soial science.2013;14:p 27-30

6 Shah C K Meheta.H.study of injuries among construction workers in Ahemedebad city,Gujrat, Indian J. practising doctor.vol.5,No-6(2009-012009-02)

7 Health\& safety Executive.2002.Revitalizing Health and Safety in Construction: DiscussiodocumentSuffolk:HSE Books.2002:p-38

8 The Health Status of Construction Workers http:/ /nmmu.ac.za/documents/theses/DeaconCH.pdf
9 Stevenson CJ.occupational disease of skin.In: raffle PA,Adams PH,Boxter PJ,Lee WR, Editor.Hunter disease of occupations.8th ed.London:Edward Arnold; 1994.p691-719

10 Puri.R.prevalence risk factors and traditional ttreatments of genital prolapsed in Manma, Kalikot District, Nepal:A community based Population Study. august.2011faculty of health science.University of TROMO.Norway

11 Gurav RB, Kartikeyan S, Wayal K,Joshi Sd. Assessment of Health profile of daily wage labours.Indian J. Occup Environ Med 2005;9:115-7

12 Sarma. N, Occupational allergic contact dermatitis among construction worker in India. Indian $\mathrm{J}$. dermatol.2009 April-June 54(2):137-141

13 Park. K, editor.Park's Textbook of Prenentive and Social Medicine.17th edn.Jabajpur.Bnarsidas Bhanot Publishers;2002:p 574-88 